\title{
Biofiltración con un sistema de tres lechos de compost para la remoción de sulfuro de hidrógeno
}

\section{Biofiltration with a system of three beds of compost for the removal of hydrogen sulfide}

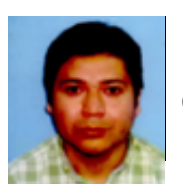

\section{Bustamante Loyola Nelson Williams}

Qco. Electroquímico Ing. Magister en Aplicaciones de Ingeniería Ambiental (Pontífice Universidad Católica del Norte de Chile).nwbustamante@uce.edu.ec. Sede Galápagos, Universidad Central del Ecuador.

\section{Resumen}

Las plantas de tratamiento de aguas residuales y otras fuentes se han visto en la necesidad de buscar métodos para tratar las emisiones gaseosas y de esta forma cumplir con las normas ambientales vigentes. Estas industrias deben solucionar las emisiones de los olores de sulfuro de hidrógeno. Una alternativa viable es la biofiltración, la cual es responsable de la remoción de un gran número de contaminantes gaseosos, entre los cuales se encuentra el sulfuro de hidrógeno. Esta técnica ofrece interesantes garantías para el medio ambiente y es económicamente atractivo para las empresas, debido a que puede significar un ahorro en los insumos utilizados para los tratamientos establecidos en el tratamiento de olores. Por lo tanto, aprovechando las características de la biofiltración se puede dar solución a la emisión de olores proveniente del sulfuro de hidrógeno y extender el uso de la técnica para la eliminación de ciertos compuestos contaminantes gaseosos. Por esta razón se desarrolla el presente trabajo de investigación y se enfoca en la construcción de un sistema de biofiltro piloto, para eliminar sulfuro de hidrógeno y de esta manera obtener información acerca de la máxima capacidad de remoción en un biofiltro.

La metodología que se utilizó, para la puesta en marcha del sistema de biofiltración, se consideró: La preparación de material de soporte, la inoculación de bacterias oxidantes de sulfuros, la preparación de los nutrientes para el compost y la operación del sistema de biofiltración. Cada una de estas etapas se ejecutó exitosamente, logrando un funcionamiento eficiente del sistema. Esto se refleja en el resultado final, que corresponde a remover 1.250 ppm y 1.300 ppm de sulfuro de hidrogeno, con una eficiencia del 100\%.

Por lo tanto, es una técnica viable y posible de implementarla en cualquier tipo de Planta de Tratamiento de Aguas Servidas, para la mitigación de olores derivados del sulfuro de hidrógeno.

Palabras clave: biofiltración; aguas servidas; olores, sulfuro de hidrógeno; bacterias oxidantes de sulfuros y contaminantes

\section{Abstract}

In order to comply with current environmental standards, wastewater treatment plants and other industries have found it necessary to seek out methods for gaseous emissions treatment. Consequently, such industries must address hydrogen sulfide odor emissions. Biofiltration, responsible for the removal of a large number of gaseous pollutants including hydrogen sulphide, is a viable option. Offering interesting guarantees for the environment, this technique is economically attractive for companies where savings can be obtained in the treatment of odors through the inputs used in established treatments. Taking advantage of the characteristics of biofiltration may extend the use of the technique for the elimination of certain gaseous pollutant compounds and provide a solution to hydrogen sulfide odor emissions. It is for this reason that the present research study has been developed and why focus has been given to the construction of a pilot biofilter system to remove hydrogen sulphide in order to determine the maximum removal capacity of a biofilter. 
The methodology used for the implementation of the biofiltration system was: Preparation of support material; inoculation of sulfur oxidant bacteria; preparation of nutrients for compost; and the operation of the biofiltration system. Each of these stages was executed successfully whereby achieving the efficient operation of the system reflected in the final result which corresponds to removing 1,250 ppm and 1,300 ppm of hydrogen sulphide with an efficiency of $100 \%$. With possibilities for implementation into any type of Sewage Treatment Plant, the biofiltration system is no doubt a feasible technique for the mitigation of odors derived from hydrogen sulphide.

\section{Keywords: biofiltration; sewage; odours; hydrogen sulphide; sulphur oxidant bacteria and contaminants}

\section{Introducción}

La emisión de olores molestos por establecimientos industriales se ha transformado en una problemática de difícil solución, sobre todo para aquellas industrias que se encuentran insertas dentro del núcleo urbano.

Entre las actividades industriales que contribuyen a la generación de gases y olores se pueden destacar los procesos de las industrias de las celulosas, las pesqueras, las mineras y las de tratamiento de aguas. Durante estos procesos se liberan una variedad de sustancias que producen malos olores, entre las cuales se encuentran el metil mercaptano, dimetil sulfuro y dimetil disulfuro. A este tipo de compuestos se les denomina TRS (Total Reduced Sulfur: Azufre Reducido Total). Estos olores son originados, por condiciones que se ocasionan en medios que favorecen la formación de sulfuro de hidrógeno. Este gas es el principal, que plantea problemas de corrosividad, toxicidad y de quejas sociales al ser fácilmente detectado. Actualmente, para prevenir los riesgos de la contaminación por olores, se han considerado sistemas de tratamientos fisicoquímicos y biológicos (Biofiltración) [11]. A pesar de que los sistemas fisicoquímicos (condensación adsorción y absorción) se caracterizan en general por tener altas eficiencias de eliminación, presentan la desventaja de que los contaminantes solo son transferidos de una fase a otra generando una corriente que será necesario disponer sus residuos utilizando otro tratamiento. También demandan altos consumos de reactivos y tienen altos requerimientos de energía que encarecen su costo.

La biofiltración es una de las técnicas biológicas mas utilizada para el control o tratamientos de olores, debido a que presenta una tecnología eficiente y económica. En esta técnica los microorganismos son los responsables de la degradación biológica de los contaminantes volátiles y compuestos inorgánicos contenidos en corrientes de aire residual. La biofiltración se aplica, por ejemplo, en el tratamiento de amoníaco, sulfuro de hidrógeno, monóxido de carbono, acetona, benceno, butanol, acetato de butilo, dietilamina, disulfuro de dimetilo, etanol, hexano, etilbenceno, butilaldehido, metanol, metiletilcetona, estireno, isopropanol, metano, metilmercaptano, mono-di-triclorometano, óxido de nitrógeno, dióxidos de nitrógeno, pentano, sulfuro de dimetilo, tiofenos, tolueno, tricloroetano, tetracloroetano, 2-etil-hexanol y xileno [13]. Muchos de estos compuestos se generan en las industrias de las pulpas del papel, de productos químicos, petroquímicas y alimenticias [19].

En los últimos años, las investigaciones de la biofiltración se han enfocado a la creación de sistemas con mejor control de los procesos y comprender mejor los sistemas de biofiltración. La tendencia actual involucra el perfeccionamiento de la biofiltración tradicional hacia equipos de alto desempeño para el tratamiento de emisiones con concentraciones altas de compuestos contaminantes, utilizando microorganismos previamente seleccionados y adaptados. Sin embargo, existen limitados reportes acerca de la implementación de este tipo de procesos a nivel industrial.

Por lo tanto, aprovechando las características de la biofiltración se puede dar solución a la emisión de olores proveniente del sulfuro de hidrógeno y extender el uso de la técnica para la eliminación de ciertos compuestos contaminantes gaseosos. Por esta razón se desarrolla la presente investigación y se enfoca en la construcción de un sistema de biofiltro piloto, para eliminar sulfuro de hidrógeno y de esta manera obtener información acerca de la máxima capacidad de remoción en el biofiltro.

\section{Materiales y metodología}

Con el propósito de construir un biofiltro piloto para la remoción de sulfuro de hidrogeno se diseñó un sistema piloto para la simulación de la eliminación del contaminante a través de los componentes que se detallan en el siguiente diagrama Fig.1:

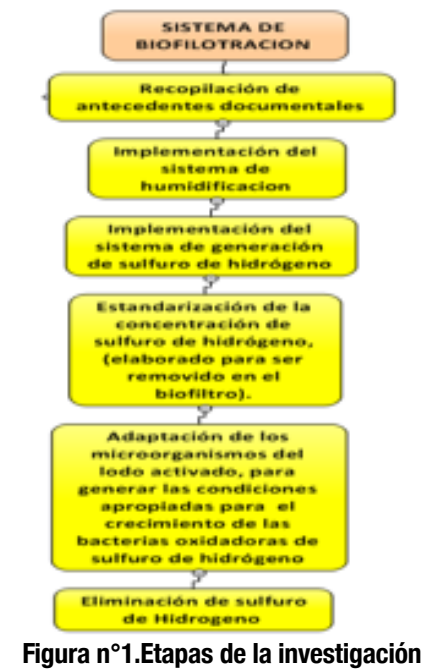

a. Implementación del sistema humidificación

Para una operación eficiente del biofiltro, el medio 
filtrante debe tener una humedad de $60 \%$. Por lo tanto, se contó con una columna de humidificación para humedecer el aire que transportó el gas contaminante. La columna de humidificación fue construida de material de PVC, sus dimensiones fueron: 7,0 $\mathrm{cm}$ de diámetro, $70 \mathrm{~cm}$ de altura y su capacidad fue de 2,1 litros. Además, su interior se rellenó con trozos de PVC tipo Rashig de $1,0 \mathrm{~cm}$ de diámetro y se instaló un aspersor que permite la dosificación del agua. Para la distribución de agua y aire se utilizan mangueras de $1 / 2$ pulgada.

b. Implementación del sistema de generación de sulfuro.

La columna generadora debe tener las mejores condiciones de operación y de estructura, para producir sulfuro de hidrogeno. La columna es de material de acrílico, su dimensión fue: $7,0 \mathrm{~cm}$ de diámetro, $50 \mathrm{~cm}$ de altura y su capacidad fue 1,2 litros. Su interior se rellenó con esferas de vidrio de $1,0 \mathrm{~cm}$ diámetro (para obtener un contacto estrecho entre los reactivos). Para la distribución de los reactivos se utilizaron mangueras de 0,6 cm de diámetro y para la distribución de aire se utilizaron mangueras de $1,2 \mathrm{~cm}$ de diámetro [1].A continuación, se describe los pasos, seguidos, para la puesta en marcha de la columna generadora de sulfuro de hidrógeno:

\section{Preparación de reactivos}

Los reactivos se prepararon tomando las medidas de seguridad, considerando la hoja de seguridad de cada sustancia.

Para realizar la preparación de las soluciones se siguieron los siguientes pasos:

- Preparación de una solución 0,0625 M de sulfuro de sodio. Se pesaron $300 \mathrm{~g}$ de sulfuro de sodio y se aforó con agua destilada hasta los 20 litros.

- Preparación de una solución 0,1250 M de ácido clorhídrico. Se midieron $100 \mathrm{ml}$ de ácido clorhídrico concentrado y se aforó con agua destilada hasta los 20 litros.

c. Estandarización de la concentración de sulfuro de hidrógeno, que se utiliza para ser removido en el biofiltro.

La estandarización de la concentración del sulfuro de hidrogeno se realizó para asegurar que la columna generara una concentración regular de gas contaminante.

Considerando lo anterior, a la columna generadora de sulfuro de hidrógeno, se le adicionó gota a gota las soluciones de 0,0625 $\mathrm{M}$ de Na2S y $0,125 \mathrm{M} \mathrm{HCl}$ obteniendo un flujo de $0,038 \mathrm{ml} / \mathrm{s}$ de producto [1]. Este entró en contacto con las esferas de vidrio de $1,0 \mathrm{~cm}$ de diámetro y generó instantáneamente el sulfuro de hidrogeno. Al mismo tiempo, se fijó un flujo de aire (5,0 L/min o $10 \mathrm{~L} / \mathrm{min})$ humidificado, para arrastrar el gas generado.

La generación de sulfuro de hidrógeno se presenta en la siguiente ecuación:

$\mathrm{Na} 2 \mathrm{~S}(\mathrm{ac})+2 \mathrm{HCl}(\mathrm{ac}) \mathrm{H} 2 \mathrm{~S}(\mathrm{~g})+2 \mathrm{NaCl}(\mathrm{ac})$

La medición de las concentraciones de sulfuro de hidrógeno se realizó mediante el método gravimétrico y el método colorimétrico de tubos Dräger.

Procedimiento del método gravimétrico: El método gravimétrico aplicado en este ensayo, se basa en la formación de un precipitado de sulfuro de cobre. La reacción involucrada se representa en la siguiente ecuación química:

$$
\mathrm{H} 2 \mathrm{~S}(\mathrm{~g})+\mathrm{CuSO} 4(\mathrm{ac}) \mathrm{CuS}(\mathrm{s})+\mathrm{H} 2 \mathrm{SO} 4(\mathrm{ac}) \quad \mathrm{Ec} .
$$

Al sistema generador de sulfuro de hidrogeno se le anexó una trampa que contiene una solución de sulfato de cobre 0,1 M. Por lo tanto, el sulfuro de hidrogeno producido reacciona con el sulfato de cobre, formando un sólido azul oscuro (sulfuro de cobre) (Fig. 2). El producto se filtró al vacio y se dejó secar por 24 horas a $90^{\circ} \mathrm{C}$. Luego se pesó y se determinó la concentración de sulfuro de Hidrogeno.

\section{Procedimiento del método colorimétrico}

El sistema de medición colorimétrico está compuesto por un tubo Dräger y una bomba de detección de gases marca Accuro modelo ARAA-F001 (Fig.3). Cada tubo Dräger contiene un sistema de reacción altamente sensible. Estas exigencias están fijadas tanto en normas internacionales como nacionales sobre tubos de medición.

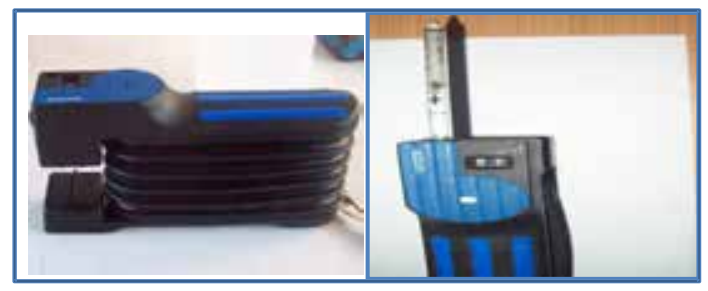

Figura 3. Equipo Accuro ARAA-F001

Para la medición se seleccionaron los tubos Dräger de sulfuro de hidrogeno de rango de 100 ppm - 2000 ppm, los cuales tienen una precisión de 5,0\%. Para la medición se aspiró un volumen determinado (100 $\mathrm{ml}$ calibrados) de gas a través del tubo. Luego se dejó reaccionar el gas por 30 segundos, esperando que se produzca un cambio de color en un rango fácilmente detectable (Fig.4).

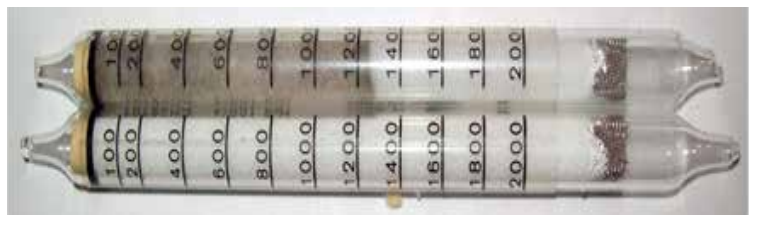

Figura 4. Etapas de la investigación

Adaptación de los microorganismos del lodo activado, para generar las condiciones apropiadas para el crecimiento de las bacterias oxidadoras de sulfuro de hidrógeno. 


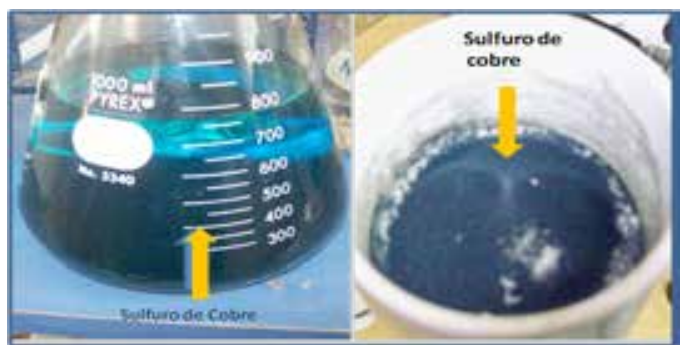

Figura 2 .Sulfuro de cobre en solución y filtrado

Para la adaptación de las bacterias utilizó un bioreactor (Fig.5) de material de acrílico de capacidad de 4 litros equipado con un termómetro Branan (escala de -20 a $50^{\circ} \mathrm{C}$ ) y un electrodo de medidor de $\mathrm{pH}$ (equipo Oyster). Este sistema trabajó con un agitador para homogeneizar el contacto entre lodo activado (proveniente de planta de tratamiento de aguas servidas) y el sulfuro de hidrógeno con aire.

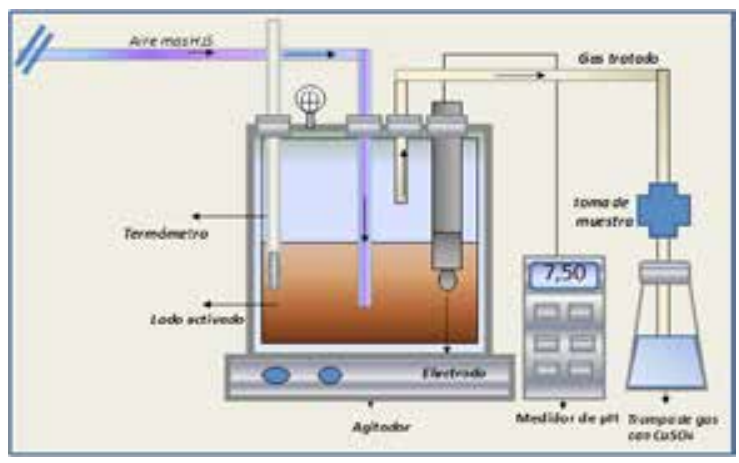

Figura 5. Etapas de la investigación

La adaptación de las bacterias, consistió en hacer crecer los microorganismos, frente a un flujo de sulfuro de hidrógeno. Para este proceso se consideraron los siguientes pasos: a. Preparación de nutrientes, b. Condiciones de crecimiento de las bacterias, c. Procedimiento de crecimiento de las bacterias y d. Determinación de $\mathrm{pH}$ y sulfato.

Las bacterias necesitan una fuente de nutrientes específica para sobrevivir y propagarse. Dentro de estos nutrientes se encuentran elementos como nitrógeno, magnesio, fósforo, potasio, azufre, magnesio, calcio, sodio y hierro. En la Tabla 1, se muestran los nutrientes agregados durante una semana al lodo activado. Se debe mencionar, que posterior a la semana de adición de nutriente se agregó el sulfuro de hidrogeno.

Tabla 1: Nutrientes adicionados para el crecimiento de bacterias oxidantes de sulfuro de hidrógeno [1]

\begin{tabular}{|l|c|}
\hline Nutrientes & Concentración(g/L) \\
\hline $\mathrm{Na}_{2} \mathrm{HPO}_{4}$ & 1,2 \\
\hline $\mathrm{KH}_{2} \mathrm{PO}_{4}$ & 1,4 \\
\hline $\mathrm{MgSO}_{4}{ }^{*} 7 \mathrm{H}_{2} \mathrm{O}$ & 0,1 \\
\hline$(\mathrm{NH} 4)_{2} \mathrm{SO}_{4}$ & 0,1 \\
\hline $\mathrm{CaCl}_{2}$ & 0,03 \\
\hline $\mathrm{FeCl}_{3}$ & 0,02 \\
\hline $\mathrm{MnSO}_{4}$ & 0,02 \\
\hline $\mathrm{Na}_{2} \mathrm{~S}_{2} \mathrm{O}_{3}$ & 10 \\
\hline
\end{tabular}

Las bacterias oxidantes son aerobias, autótrofas ya que obtienen la energía a partir de la oxidación de tiosulfato, aunque también son capaces de oxidar parcialmente otros compuestos de azufre, tales como el sulfuro de hidrogeno. Las condiciones de operación de las bacterias son: La temperatura óptima de crecimiento es de $28^{\circ} \mathrm{C}$ y el pH óptimo se encuentra entre $6,6-7,2[1]$.

Se agregaron 3,5 litros de lodo activado al bioreactor. El bioreactor se selló asegurando, que el termómetro y el sensor de $\mathrm{pH}$ quedaran bien ubicaúltimo, se transportó el sulfuro de hidrógeno al bioreactor, con un flujo de $2 \mathrm{~L} / \mathrm{min}$ de aire. La salida del sistema se conectó con una trampa, que contenía una solución sulfato de cobre $(0,1 \mathrm{M})$, para captar el sulfuro de hidrógeno que no se absorbe en el bioreator. Para verificar, que la adaptación (crecimiento) de las bacterias, se realizaron dos experiencias: medición de $\mathrm{pH}$ y medición de la concentración de sulfato en el lodo activado.

Las experiencias se realizaron adicionando 1.300 ppm de sulfuro de hidrógeno con un flujo de aire de $5 \mathrm{~L} / \mathrm{min}$ al bioreactor. La medición de $\mathrm{pH}$ fue registrada por 42 horas. Para el caso de la determinación de la concentración sulfato, los datos fueron tomando cada dos horas hasta completar 24 horas.

a. Diseño y puesta en marcha del biofiltro

El biofiltro se fabricó con material de fierro recubierto con esmalte anticorrosivo y estuvo compuesto por tres cilindros (etapas/lechos 1,2 y 3 ) individuales de $50 \mathrm{~cm}$ de altura y $40 \mathrm{~cm}$ de diámetro (Fig.6). Cada cilindro se diseñó con una entrada de agua (o nutriente) y tres entradas de medición de parámetros de operación

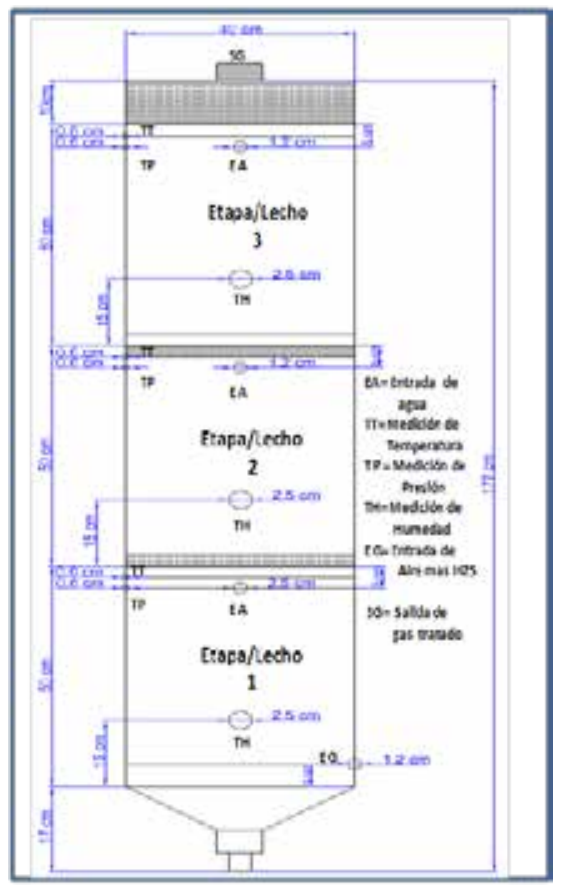

Figura 6. Biofiltro con tres lechos. 
Cada cilindro fue implementado con un sistema de aspersión, para mantener la humedad al 60\% y agregar periódicamente los nutrientes al compost. Los cilindros en el interior tienen una placa distribuidora de PVC, con agujeros de $5 \mathrm{~mm}$, para el paso del sulfuro de hidrógeno a los respectivos lechos fijos.

El diseño del equipo se realizó para un biofiltro que cumpla las condiciones que se presentan en la Tabla 2.

\section{Tabla 2. Condiciones de diseño del biofiltro}

\begin{tabular}{|l|l|l|l|l|l|}
\hline $\begin{array}{l}\text { Flujo (L/ } \\
\text { min) }\end{array}$ & $\begin{array}{l}\text { Tiempo total } \\
\text { de Residen- } \\
\text { cia (min) }\end{array}$ & $\begin{array}{l}\text { Radio } \\
\text { del } \\
\text { Biofiltro } \\
(\mathrm{cm})\end{array}$ & $\begin{array}{l}\text { Altura } \\
\text { total de } \\
\text { lecho } \\
(\mathrm{cm})\end{array}$ & Vol. & $\begin{array}{l}\text { Conc. de } \mathrm{H}_{2} \mathrm{~S} \\
\text { de entrada } \\
(\mathrm{L})\end{array}$ \\
\hline 5 & 15.8 & 20 & 90 & 9,2 & 1250 \\
\hline 10 & 7.90 & 20 & 90 & 9,2 & 1300 \\
\hline
\end{tabular}

Elaborado por el autor Escucha r/ Leer fonéticamente / Diccionario - Ver diccionario detallado

El volumen efectivo de reacción es el volumen de compost sobre el cual se produce la degradación del contaminante. Este se calculó corrigiendo el volumen del lecho filtrante con la porosidad. Se realizaron ensayos de humedad en el biofiltro, con el propósito determinar la perdida de agua en el compost durante la circulación de aire en el biofiltro. Para esta actividad se cargó $18,8 \mathrm{Kg}$ de compost (con humedad de $60 \%$ ), luego se unió a la columna de humidificación y se circuló aire a distintos flujos (5.0 L/min y $10 \mathrm{~L} / \mathrm{min}$ ).

El material de soporte que se seleccionó, para la puesta en marcha del biofiltro fue compost comercial, debido a sus propiedades fisicoquímicas (porosidad, densidad aparentes etc.), y por los buenos resultados que se han reportado [20].Se determinaron las propiedades fisicoquímicas del compost. Se obtuvieron valores de densidad aparente de 0,55 g/ $\mathrm{ml}$, porcentaje de porosidad de $70 \%$ y pH de 7,4. Además, se le realizó una granulometría para definir el tamaño de partícula de trabajo $(0,6 \mathrm{~cm}-1,0 \mathrm{~cm})$. La humedad se fijó en $60 \%$, respetando el rango recomendado por la bibliografía [20]. Una vez caracterizadas las propiedades del compost, se procedió a preparar el compost, homogeneizando sus partículas y agregando conchuelas marinas, para estabilizar el $\mathrm{pH}$. La proporción que se utilizó fue de $6: 1(18,6 \mathrm{Kg}$ de compost por 3,1 Kg de conchuelas de mar).

El inoculo se agregó con una proporción 3:1 a los lechos del biofiltro. Este volumen ( $\mathrm{L}$ de lodo activado diluido por etapa) fue igual al volumen que se debe agregar al compost para alcanzar una humedad del $60 \%$. Se prepararon $20 \mathrm{~L}$ de nutrientes (especificados en la Tabla 1), el cual se conectó al biofiltro. En general la adición de nutrientes se realizó en los periodos que el biofiltro estuvo fuera de servicio (cada seis días).

La puesta en marcha del biofiltro se comenzó, preparando los cilindros (lecho 1,2 y 3) con la mezcla de compost y conchuelas. A continuación, se ensambló cada etapa, para armar el biofiltro, el cual se conectó al sistema de humidificación y generación de sulfuro de hidrógeno, para implementar el sistema de remoción de sulfuro de hidrógeno.

La operación empezó, haciendo circular una corriente de aire, para verificar las fugas. El aire que se inyectó al sistema, circuló previamente por una trampa de retención de líquidos (agua contaminada o lubricante) y un filtro (de carbón activado) para asegurar que no pasen partículas que contaminen el sistema. Luego se agregó a cada cilindro, el inóculo de lodo activado en una solución 3:1. Una vez que todo el sistema estaba en buenas condiciones, se generó el sulfuro de hidrógeno. Este gas se transportó por una corriente (flujo definido previamente) de aire hacia las etapas del biofiltro, en donde se trató de acuerdo a los parámetros operacionales fijados. El circuito se terminó conectando la salida del biofiltro con una trampa con sulfato de cobre, para detectar el sulfuro de hidrógeno (Fig.7).

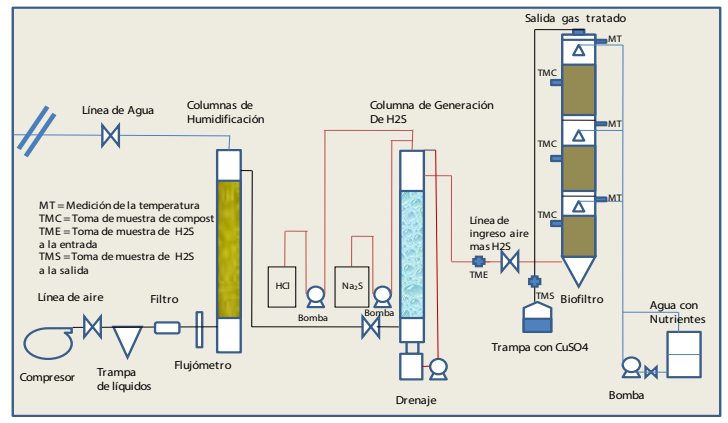

Figura $n^{\circ} 7$ : Sistema de biofiltarcion piloto.

\section{Resultados y discusión}

De acuerdo a la metodología, se construyó la columna humidificadora con los accesorios necesarios del sistema. La importancia de la columna es que, produce la humidificación del aire, para reponer la humedad en el material de soporte, que tiene el biofiltro. El sistema se ejecutó haciendo pruebas de variaciones de flujos y se detectaron las fugas en áreas localizadas de la columna, las cuales fueron corregidas, sellando con silicona industrial las zonas afectadas. La presencia de estas fugas podría influir en la humedad de los lechos y a las variables de operación del sistema.

En relación al sistema generador de Sulfuro de Hidrogeno se obtuvieron los resultados esperados, puesto que los ensayos realizados probaron que la columna era eficiente para la generación de sulfuro de hidrógeno. Para obtener el sulfuro de hidrogeno la interacción entre los reactivos debe ser íntima, para lograr esto se agregaron esferas de vidrios en el interior de la columna [1]. Con respecto a esto se logró una instantánea formación del gas. Para asegurar que la generación de sulfuro de hidrógeno, corresponde a las concentraciones fijadas en el 
estudio, se reguló el flujo de sulfuro de sodio y ácido clorhídrico y se midieron las concentraciones producidas de sulfuro de hidrógeno (Tabla 3).

Tabla 3:

\begin{tabular}{|c|c|c|c|c|c|}
\hline $\begin{array}{l}\text { Tiem. } \\
\text { (Hrs) }\end{array}$ & $\begin{array}{l}\text { Temp. } \\
\left({ }^{\circ} \mathrm{C}\right)\end{array}$ & $\begin{array}{l}\text { Flu- } \\
\text { jo } \\
\text { de } \\
\text { aire } \\
\text { ( L/ } \\
\text { min) }\end{array}$ & $\begin{array}{l}\text { Flujo } \\
\text { de do- } \\
\text { sific. de } \\
\text { reac- } \\
\text { tivos( } \\
\mathrm{ml} / \mathrm{s})\end{array}$ & $\begin{array}{c}\text { Conc. de } \\
\mathrm{H}_{2} \mathrm{~S} \\
(p p m) \\
\text { (gravimetría) }\end{array}$ & $\begin{array}{l}\text { Conc. de } \mathrm{H}_{2} \mathrm{~S} \\
(\mathrm{ppm}) \\
\text { (colorimetría)a) }\end{array}$ \\
\hline 3 & 30 & 5 & 0,038 & 1200 & 1250 \\
\hline 6 & 29 & 5 & 0,038 & 1270 & 1300 \\
\hline 9 & 28 & 10 & 0,033 & 1250 & 1350 \\
\hline 12 & 29 & 10 & 0,033 & 1380 & 1390 \\
\hline
\end{tabular}

Figura ${ }^{\circ}{ }^{8}$ : Relación del medo gravimétrico vs colorimétrico

En las concentraciones obtenidas se puede observar, que el método gravimétrico mostró un promedio de concentraciones de sulfuro de hidrogeno de 1275 ppm y el método colorimétrico mostró un promedio de concentraciones de sulfuro de hidrogeno de 1317,5 ppm (Tabla 3 y Fig. 8). La diferencia se observa en la mejor linealidad $(r=0,998)$ de los datos del método colorimétrico respecto al gravimétrico.

La Implementación del bioreactor se realizó, para la adaptación de los microorganismos, debido a que es un sistema en donde se pueden controlar las condiciones de crecimiento de las bacterias oxidadoras de sulfuro de hidrogeno. El sistema cuenta con la posibilidad de regular los flujos de gas en la entrada y salida, puesto que se producen diferencia de presiones, generando una pérdida de lodo activado desde el bioreactor. Este sistema debe ser desmontable y de fácil acceso para el control de las variables (Temperatura y $\mathrm{pH}$ )

La adaptación de las bacterias se realizó para estimular el enriquecimiento de los microorganismos, capaces de degradar el sulfuro de hidrogeno. Con el propósito de establecer, que la adaptación de las bacterias oxidadoras de sulfuro de hidrógeno, se estaba efectuándose, se realizaron las experiencias, que corresponde a la medición de $\mathrm{pH}$ y concentración de sulfato en el lodo activado. De acuerdo a la metodología presentada, se obtuvo los siguientes resultados de la variación del pH y la concentración de sulfato respecto al tiempo.

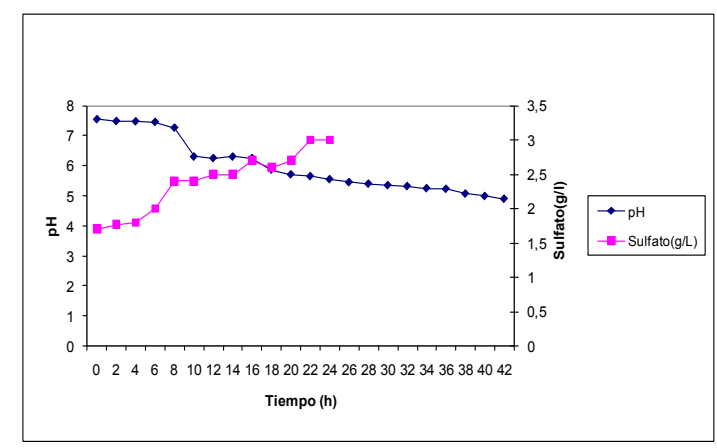

Figura 9: Efecto del pH y sulfato en el lodo activado

Lodo (microorganismos)+ H2S (eq) +2O2 (g) SO4 $-2(\mathrm{ac})+2 \mathrm{H}+(\mathrm{ac})+$ Lodo Éc. (3)
La gráfica muestra una concentración inicial de 1.7 $\mathrm{g} / \mathrm{L}$ de sulfato, esto se debe a que por una semana se estuvo agregando nutrientes (elementos con sulfatos) antes que se adicionara el sulfuro de hidrógeno. Se debe considerar, que al agregar sulfuro hidrogeno se observa en la gráfica, una variación a $3.0 \mathrm{~g} / \mathrm{L}$ de sulfato (a las 24 horas), esto significa un aumento de $1.3 \mathrm{~g} / \mathrm{L}$, similar a lo que reporta [10], en su estudio, el cual es un aumento de $1.9 \mathrm{~g} / \mathrm{L}$ de sulfato en 25 horas aproximadamente.

El biofiltro se encuentra dividido en tres lechos (Fig. 6 ). Esta configuración permite tener un amplio control sobre el sistema de tratamiento global, ya que, en caso de falla, será posible aislar el lecho dañado y proceder a su reparación sin necesidad de detener el proceso de biofiltración. Por otro lado, si el flujo de gases a tratar aumenta, se tendrá la posibilidad de adherir al sistema un nuevo filtro en paralelo [5]. La configuración en varios lechos, previene además la excesiva compactación que se produciría si se tuviera un solo lecho de gran superficie. Al ser independiente cada lecho, las variables de operación se controlan de manera individual. Además, cada lecho esta implementado con aspersores, los cuales facilita el ingreso de nutriente o agua para el compost.

La puesta en marcha del sistema de biofiltración, considera los siguientes pasos: a. Preparación de material de soporte, b. Inoculación al compost, c. Preparación de los nutrientes para el compost y d. Operación del sistema de biofiltracion.

a. La preparación del compost fue la correcta, debido a que sus lechos pudieron mantener la humedad requerida, por otra parte, los lechos no sufrieron taponamiento, debido a su buena porosidad y tamaño de partícula. La duración del material de soporte se puede optimizar manteniendo eficientemente las condiciones de operación. El resultado nos permite mencionar, que el compost es un excelente material de soporte gracias a su alto potencial de retención de humedad, pH neutro, elevada porosidad y a sus microorganismos [20].

b. La inoculación de bacterias adaptadas mostro que fue un aporte al compost, debido a que esto permitió la degradación del sulfuro de hidrógeno y el buen desempeño del biofiltro.

c. La preparación de los nutrientes para el compost consistió en una solución de 20 litros de nutrientes, en las proporciones indicadas en la Tabla $\mathrm{n}^{\circ} 1$. Los nutrientes se deben agregar en el momento que se suspenda la alimentación del gas contaminante, puesto que son fuente de energía para las bacterias oxidadoras de sulfuro de hidrógeno.

d. La operación del biofiltro, se realizó circulando sulfuro de hidrogeno, primero a un flujo de aire 
de $5 \mathrm{~L} / \mathrm{min}$ por un periodo de seis días, luego a $10 \mathrm{~L} / \mathrm{min}$ por un periodo de seis días. El propósito de cambiar flujo fue aprovechar las características de diseño (volumen total y configuración de los lechos), lo que permite probar la remoción de concentraciones altas de sulfuro de hidrógeno.

A continuación, se presentan los resultados de la puesta en marcha del biofiltro:

Tabla n4: Resultados de las condiciones de operación a un flujo de $5 \mathrm{~L} / \mathrm{min}$ después de seis días.

\begin{tabular}{c|c|c|c|c}
\hline $\begin{array}{c}\text { Lecho/ } \\
\text { Etapa }\end{array}$ & $\begin{array}{c}\text { Temp. } \\
\left({ }^{\circ} \mathrm{C}\right)\end{array}$ & $\mathrm{pH}$ & $\begin{array}{c}\% \text { Hume- } \\
\text { dad }\end{array}$ & Conc. de $\mathrm{H}_{2} \mathrm{~S}(\mathrm{ppm})$ \\
\hline 1 & 31 & 5.00 & 52,2 & 1250 (entrada) \\
2 & 25 & 6.50 & 54,5 & No se registro \\
3 & 25 & 7.00 & 54,3 & $<0.2$ ppm (salida) \\
\hline
\end{tabular}

[2], señala que en el interior del biorreactor se incrementa la temperatura, cuando los microorganismos son más activos, lo que se produce en un rango de 28-32 ${ }^{\circ} \mathrm{C}$. Sin embargo, cualquier cambio en las condiciones de operación puede afectar la eficacia de degradación del sistema. Se observa además que la remoción de sulfuro de hidrogeno es un $100 \%$, es decir se degrada completamente las 1,250 ppm de gas.

Tabla 5: Resultados de las condiciones de operación a un flujo de 10L/min, después de doce días.

\begin{tabular}{|c|c|c|c|c|}
\hline Lecho/Etapa & Temp. $\left({ }^{\circ} \mathrm{C}\right)$ & $\mathrm{pH}$ & $\begin{array}{c}\% \text { Hume- } \\
\text { dad }\end{array}$ & $\begin{array}{c}\text { Conc. de entra- } \\
\text { da } \mathrm{H}_{2} \mathrm{~S}(\mathrm{ppm})\end{array}$ \\
\hline 1 & 32 & 4,50 & 54,2 & 1300 (entrada) \\
\hline 2 & 26 & 5,80 & 55,8 & No se registro \\
\hline 3 & 25 & 6,50 & 55,5 & $<0.2$ ppm (salida) \\
\hline
\end{tabular}

Se observa además que la remoción de sulfuro de hidrogeno es un $100 \%$, es decir se degrada completamente las 1,300 ppm de gas. El biofiltro ha demostrado ser altamente eficaz en la eliminación de sulfuro de hidrogeno en flujos de $5 \mathrm{~L} / \mathrm{min}$ y $10 \mathrm{~L} / \mathrm{min}$ que corresponden a tiempos de residencia de gas de 15.8 min y 7.9 min respectivamente. Se probó un $100 \%$ de eficiencia para todas las concentraciones de entrada ensayadas.

El artículo de [14], reporto resultados de eficiencia de eliminación de un 100\% para una concentración de 1,968 ppm de sulfuro de hidrógeno, en condiciones similares a la desarrollada en este trabajo.

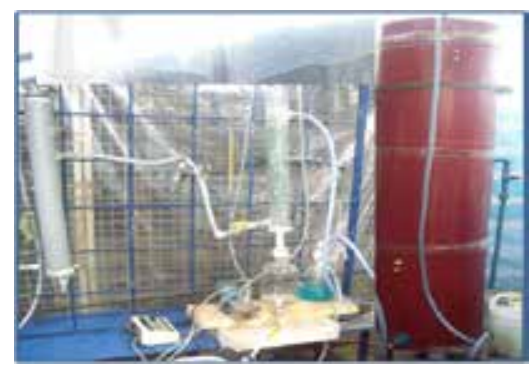

Figura 10. Sistema de prueba de biofiltracion con tres lechos, para la remoción de sulfuro de hidrogeno

\section{Conclusiones y recomendaciones}

La tecnología de biofiltración es una buena solución para el control de olores de sulfuro de hidrógeno, debido a las altas eficiencias de eliminación que ofrece, al costo moderado de inversión y la facilidad en la operación del sistema. Siguiendo esta visión se planteo la implementación del sistema de biofiltración, obteniendo las siguientes conclusiones

Uno de las principales preocupaciones para la operación de un biofiltro es mantener el grado adecuado de humedad a través del sistema. Puesto que sirve para mantener y formar la biopelicula, que se forma en el material de soporte, la cual permite que se produzca la degradación del sulfuro de hidrogeno. Respecto a este tema, se logró construir y poner en marcha el sistema de humidificación para el sistema.

Se logró implementar el sistema de generación de sulfuro de hidrógeno eficientemente, puesto que se pudo producir sulfuro de hidrógeno controlando su concentración entre 1.250 ppm y 1.300 ppm.

La adaptación, consistió en adaptar, a las bacterias oxidantes durante dos semanas, al sulfuro de hidrógeno. Para este proceso se consideró: la preparación de nutrientes, condiciones de creci-miento y los ensayos de determinación de $\mathrm{pH}$ y sulfato. Actividades que se lograron completa-mente, permitiendo estimular el crecimiento de las bacterias oxidantes de sulfuro de hidrógeno.

El sistema de biofiltración diseñado, se compone de un sistema de humidificación, una columna de generación de sulfuro de hidrogeno y un biofiltro. Este sistema se encuentra dividido en tres lechos, lo que permite tener un amplio control sobre el sistema de tratamiento global, ya que, en caso de falla, será posible aislar el módulo dañado y proceder a su reparación sin necesidad de detener el proceso de biofiltración. La configuración en varios lechos, previene además la excesiva compactación que se produciría si se tuviera un solo lecho de gran superficie. Por lo tanto, se logró diseñar e instalar el sistema de biofiltración, considerando todas las metologías propuestas.

Para la puesta en marcha del sistema de biofiltración, se consideró: La preparación de material de soporte, la inoculación al compost, la preparación de los nutrientes para el compost y la operación del sistema de biofiltración. Cada una de estas etapas se ejecutó exitosamente, logrando un funcionamiento eficiente del sistema. Esto se refleja en el resultado final, que corresponde a remover 1.250 ppm y 1.300 ppm de sulfuro de hidrogeno, con una eficiencia del $100 \%$. 


\section{Recomendaciones}

Se recomienda realizar estudios de parámetros operacionales. (Variación de Flujos respeto a las concentraciones), para establecer las mejores condiciones de operación del sistema de biofiltración.

Para evitar la generación química de sulfuro de hidrógeno, se recomienda utilizar un cilindro con gas comprimido. Con esta medida se evita la manipulación de ácido clorhídrico y sulfuro de sodio, lo que implica disminuir los riesgos asociados al trabajo.

Como el sulfuro de hidrógeno es un gas muy tóxico, se recomienda tener un sistema de extracción adecuada, para realizar las pruebas de remoción de sulfuro de hidrógeno.

Si se desea obtener datos de concentraciones de sulfuro de hidrógeno más precisas, se recomienda utilizar la técnica de cromatografía de gases. Esta técnica se puede colocar en línea, para saber la concentración inmediata del sulfuro de hidrógeno.

Se sabe que existen varios tipos de bacterias oxidadoras de sulfuro de hidrógeno, sería importante caracterizar y aislara la bacteria, para sacarle mejor rendimiento y tener más certeza en las estrategias de la adaptación de estos microorganismos.

La mantención y conservación del biofiltro es importante, para el desempeño de este equipo. Por esta razón, se recomienda, que el material de confección del equipo sea inerte al sulfuro de hidrógeno (por ejemplo: fibra de vidrio).

Para asegurar la eficiencia del material de soporte, se recomienda caracterizar el compost en término de componentes químicos y carga biológica.

Está demostrado que el sulfuro de hidrógeno se puede remover utilizando compost, sin embargo, sería recomendable hacer pruebas con otros materiales orgánicos para analizar las distintas características y duración de los lechos.

\section{Referencias bibliográficas}

[1]. Aroca, G., Urrutia, H., Núñez, D., Oyarzún, P., Arancibia, A., Guerrero, K.,. "Comparison on the removal of hydrogen sulfide in biotrickling filters inoculated with Thiobacillus thioparus and Acidithiobacillus thiooxidans". Electron. J.

[2]. Braur T. and M. Madigan, "Microbiologia", Prentice Hall Hispanoamericana S.A.,Mexico, (2002).

[3]. Deshusses M.,." Biodegradation of mixtures of ketone vapours in biofilters for the treatment of waste air". Thesis for the degree of Doctor of Technical Sciences. Swiss Federal Institute of technology Zurich, (1994).

[4]. Deshusses M., Cox.. "Single-Stage H2S and VOC Removal in Bio trickling Filters and Biofilters: A Comparative Study at the Hyperion Treatment Plant", (1999)

[5]. Devinny J., Deshusses M., Webster T., "Biofiltration for air poIlution control”, Ed. Lewis, 299 pp., (1999).
[6]. Hodge D.S., Medina D.F., Islander R. and Devinny S.S., "Biofiltration of hydrocarbon fuel vapors in biofilters" Environmental Technologie, 12, pp. 655-662, (1991).

[7]. Kennes C., Thalasso F." Waste gas Biotreatment Technology". J. Chem. Biotechnol 72, 303 - 319, (1998).

[8]. Martin R., Mihelcic J., Crittenden J.. " Design and performance characterization strategy using modelling for biofiltration control of odours hydrogen sulphide". Journal of the Air and Waste Management Association, (2004).

[9]. Moreno C. J. "Compotaje", Ediciones, Mundi-Prensa, Madrid. Pp. 75 y 93, (2008).

[10]. Ramírez M. M.. "Viabilidad de un proceso para la eliminación conjunta de H2S y NH3 contenido en efluentes gaseosos". Tesis para optar al grado de doctor por la universidad de Cádiz. Pag.9-12, (2007).

[11]. M. Ramirez, K. Sedmikova, J.M Gómez, J. Paca and D. Cantero." Removal of hydrogen sulphide by immobilized Acidithiobacillus thiooxidans in a Biotrickling filter packed with polyurethane foam". Electronic Journal of Biotechnology ,(2007).

[12]. Ross M, Fraser Smith A., Shurb D.,. "Glen Cairn Trunk sewer pilot biofilter Water Environment" Association of Ontario 31st Annual Technical Symposium Hamilton Convention Centre Hamilton, Ontario (2002).

[13[. Ottengraf S.P.P. and Van Den Oever A.H.C "Kinetics of organic compound removal from waste gases with a biological filter" Biotechnol. and Bioengrg., 25, pp. 3089-3102., (1983).

[14]. Potumarthi R.,. Anupoju G. R, Mugeraya G., and Jetty, A., "Hydrogen Sulfide Removal in Biofilter: Evaluation of a New filter Material by Immobilization of Thiobacillus sp.". International Journal of Chemical Reactor Engineering. Vol. 7 [2009], Article A17,( 2009).

[15]. Shareefdeen Z., Herner B., Webb D.,. Wilson S., "Biofiltration eliminates nuisance chemical odors from industrial air streams". Journal Ind. Microbiol. Biotechnol 30:168 - 174, (2003).

[16].Sagastume J., Revah S., Ergas, S., "Changes in physical properties of a compost biofilter treating hydrogen sulfide". Journal of the Air and Waste Management Association (2003).

[17]. Schroeder E. " Trends in application of gas-phase bioreactors". University of California. In Environmental Science \& Bio/Technology 1: 65 - 74, (2002).

[18]. "Standar Methods for Examination of Wáter and Wastewater ", 20 th Edition, 2000, 1040,reg 240.

[19].Utkin J.B., Yakimov M.M., Kozlyak E.I. and Rogozhin J.S. "Biological air purification"BioCycle, October, pp. 613-620, (1992).

$\{20\}$. Vergara, A.O., L. Molina., Alarcon, N.A., Aroca, G.E. ."Effects of gas flow rate, inlet concentration and temperature on the biofiltration of toluene vapors". Journal Environmental Management. 84,115-122, (2007).

[21]. Warren J. \& Oler R, ."Biofiltration: Fundamentals, design, and operations principles, and applications". Journal of environmental engineering, (1997)." 